\title{
LA EDUCACIÓN FORMAL, NO FORMAL E INFORMAL: UNA TAREA PENDIENTE EN LOS MUSEOS DEL PERÚ
}

\author{
FORMAL, NOT FORMAL AND INFORMAL EDUCATION: AN UNFINISHED \\ TASK IN THE PERUVIAN MUSEUMS
}

Arq. Ana María Lebrún Aspíllaga ${ }^{1}$

\section{RESUMEN}

El museo, como institución cultural de carácter educativo, tiene como una de sus funciones principales la educación. Dispone para los visitantes objetos, equipos y recursos museográficos y tecnológicos que, en su gran mayoría, no son accesibles en las escuelas y en las universidades. Al ser transmisores de cultura y, a su vez, brindar diferentes estilos de aprendizaje a partir de la educación formal, no formal e informal, generan que la experiencia de visitar un el museo sea valiosa e innovadora.

En la actualidad, estas instituciones se visualizan como un importante recurso didáctico y como parte de la formación de los individuos. El aprendizaje por descubrimiento y significativo son procesos permanentes, así como una experiencia acumulativa y de carácter individual y/o colectivo a lo largo de toda la vida que contribuye a su desarrollo cognitivo, emocional y social.

Los servicios educativos que se realizan en los museos generan relaciones con las instituciones educativas. Esos servicios deben estar compuestos por un equipo transdisciplinario que dispone de conocimientos específicos sobre las características psicológicas del visitante, con respecto a su comportamiento y procesos de aprendizaje en la exposición, motivaciones, intereses, mediante una comunicación coherente, eficiente y eficaz.

\section{Palabras clave}

Educación formal en museos, educación no formal en museos, educación informal en museos

\section{ABSTRACT}

Museums as a cultural institution of educational nature has as one of its main functions that of education, putting at service for their visitors objects, equipment and museographic and technological resources that, in most cases, are not accessible in schools and universities. These offered sources are culture transmitters and, at the same time, they deliver different learning styles starting from a formal, not formal and informal education, making the experience in the museum valuable and innovative.

Currently, these institutions see themselves as important learning resources, as part of the formation of people. The learning by discovering and significance are permanent processes as well as a cumulative experience and of an individual and/or collective nature throughout the entire life, contributing to their cognitive, emotional and social development.

1 Arquitecta. Magíster en Museología. Past Directora de museos y gestión del patrimonio histórico del Instituto Nacional de Cultura y del Museo Postal y Filatélico del Perú. Gerente General de RUTA 4 SAC Planificación y Acción Cultural.

Vicepresidenta y Directora de Proyectos Nacionales e Internacionales de Instituto RUTA 4 Investigación y Proyectos. 
The educational services offered in the museums generate relationships with educative institutions. These services must be performed by a transdisciplinary team, which possess specific knowledge about the psychological characteristics of the visitor with regard to his/her behavior and learning processes in the exposition, motivations, and interests through a coherent, efficient and effective communication.

\section{Keywords}

Formal education in museums, not formal education in museums, informal education in museums

\section{INTRODUCCIÓN}

En nuestra sociedad, la escuela formal no es la única institución educativa que colabora en la formación de cultura en los estudiantes en edad escolar y universitaria. También existen otras instancias educativas que contribuyen y colaboran para este propósito, como los museos, debido a que permiten colaborar permanentemente con la educación científica a través de un aprendizaje por descubrimiento, como un método idóneo para aplicarlo en la educación formal, debido a que los estudiantes pueden aprender utilizando conocimientos referentes a los objetos de los museos como fuente de información, a la vez, el profesor actúa como mediador o facilitador para llegar a las conclusiones más pertinentes.

Coombs y Ahmed (citado por Valdés, 1999, p. 60) denominan la educación formal al"sistema educativo altamente institucionalizado, cronológicamente graduado y jerárquicamente estructurado que se extiende desde los primeros años de la escuela primaria hasta los últimos años de la universidad". Educación no formal a "toda actividad organizada, sistemática, educativa, realizada fuera del marco del sistema oficial, para facilitar determinadas clases de aprendizaje a subgrupos particulares de la población, tanto adultos como niños". Y, educación informal a "un proceso que dura toda la vida y en el que las personas adquieren y acumulan conocimientos, habilidades, actitudes y modos de discernimiento mediante las experiencias diarias y su relación en el medio ambiente".
Coombs (citado por Valdés, 1999) enfatiza la necesidad de desarrollar medios educativos distintos de los que se desarrollan en la escuela. A estos nuevos medios los denomina educación informal y educación no formal. Con estos términos indica una variedad de procesos educativos no escolares, es decir, aquellos que se encuentran ubicados al margen del sistema convencional de enseñanza reglada.

El museo, como espacio educativo, aporta significativamente a la educación formal, no formal $e$ informal durante todas las etapas de la vida. Contribuye permanentemente en el desarrollo cognitivo, emocional y social de todos los miembros de la comunidad en general. Los procesos educativos informales, no formales y formales que se suscitan en el museo son particularmente de carácter social, ya que facilita al ciudadano el acceso físico, intelectual, emocional y social a los materiales que expone y a sus significados, a través de diversas maneras (académicas o informales, intelectuales o emocionales, obligatorias o voluntarias, intencionales o diversas, entre otras).

Los museos, en general, son espacios de experiencias enriquecedoras de socialización y aprendizaje permanente. Constituyen recursos educativos muy valiosos donde se narran historias diversas a través de la exhibición de una colección y de recursos lúdicos y tecnológicos, donde el visitante interactúa con el material en exposición. A través de todos estos elementos se puede obtener retroalimentación donde los estudiantes puedan probar, de manera práctica, lo aprendido en la escuela o la 
universidad y formarse un sentido del mundo real en el que se vive.

\section{LA EDUCACIÓN EN LOS MUSEOS}

El museo es una institución cultural que, además de sus funciones intrínsecas ya conocidas como la exhibición, conservación, investigación y promoción y difusión (Valdés, 1999), es un espacio educativo que posee mecanismos que permiten seducir al público mediante una museografía sugestiva. Asimismo, los visitantes pueden acceder a sus instalaciones en cualquier momento de su vida, sin las barreras que presentan otras instituciones culturales como los centros de investigación, universidades, entre otras.

Las posibilidades de educación de los museos no se centran netamente en el aprendizaje de conocimientos, sino, adicionalmente, en el desarrollo de la sensibilidad y del goce estético, así como en las distintas posibilidades de aprender y de relacionarse con su contenido que suscita experiencias estéticas.

Los museos son lugares para el aprendizaje, permiten a las personas desarrollar habilidades y construir conocimientos en diversos espacios y momentos a lo largo de su vida. Asimismo, la misión educativa en los museos se viene desarrollando con mayor énfasis, teniendo como base las nuevas teorías del conocimiento y del aprendizaje en los diversos contextos educativos a nivel nacional $e$ internacional.

A lo largo de los tiempos y la evolución de los museos, se han producido cambios significativos en su entorno, convirtiéndose en instituciones educativas como agente cultural y social. La aportación del museo a la educación no se limita a una etapa de la vida, sino que está presente a lo largo de toda la vida de los ciudadanos y así contribuye, eficazmente en su desarrollo cognitivo, emocional y social.

El museo, a la vez, es un agente cultural y social cuando añade, al logro de la comunicación y el aprendizaje, la creación de opinión y reflexión mediante el aporte de ideas, transmisión de valores, explicación de situaciones que procuran cambios de actitudes, promoción del respeto a la multiculturalidad. Es así que se potencia la inclusión social y genera programas especiales para poblaciones que tradicionalmente no han estado presentes en los museos.

El acceso a la cultura es un derecho del ciudadano y no un privilegio reservado para unos pocos. Por ende, las exposiciones de los museos se encuentran orientadas cada vez más a satisfacer a sus visitantes a través de sus propios intereses y necesidades, eliminando dificultades y barreras que puedan impedir que el resultado de la visita sea una experiencia positiva. Asimismo, el museo debe obtener, mantener y mejorar la autonomía de pensamiento, sentido crítico y espíritu creativo de los visitantes, porque de esta manera se estaría cumpliendo la tarea de presentar de manera significativa los objetos y los conocimientos que vienen implícitos en ellos.

\section{LA EDUCACIÓN FORMAL EN LOS MUSEOS}

La educación formal es equivalente al sistema educativo reglado, altamente institucionalizado, cronológicamente graduado y jerárquicamente estructurado que se extiende desde el jardín de infancia hasta la universidad. El proceso de aprendizaje es intencionado, programado y con un agente educativo, el profesor. (Reynoso, 2013; García, 2013). Dentro de ese criterio, Valdés (1999, p. 67) considera que:

Los objetivos educativos están
encaminados a la obtención de
títulos, créditos, grados académicos o
capacitaciónprofesional. Muchosdeestos
títulos están relacionados, de forma que
unos son imprescindibles para alcanzar
el siguiente. Esta educación reglada,
institucionalizada, aporta una formación
estándar y uniforme, habitualmente de
carácter muy intelectual y abstracto, lo
que la distancia de la realidad.

En el museo, la educación formal, es un puente entre el docente y el estudiante, asimismo el museo es el mediador entre lo que expone y sus intereses. Un método de aprendizaje en el museo es el método receptivo basado en 
una explicación comprensible y razonada de los objetos que tiene el museo (por parte del docente o del guía), lo cual permite introducir al estudiante en sus conocimientos. También es muy útil la participación participativa, activa y colaborativa de los propios estudiantes que permitirá una mejor adaptación de los guías a su ritmo de comprensión personal.

García (1988, 1997) manifiesta que, los museos pueden hacer una aportación peculiar y propia al aprendizaje formal de las disciplinas relacionadas con sus colecciones, debido a que ofrecen la experiencia única de ver, contactar y poder analizar las obras de arte auténticas $y$ los objetos originales que, entendidos como documentos, es decir, como fuentes de información primaria, favorecen la realización de un determinado tipo de visita, conectada con la adquisición de conocimientos nuevos que, unidos con los conocimientos previos generan un aprendizaje significativo.

En el museo, los estudiantes (de escuela y de universidad) pueden aprender a aprender con el patrimonio cultural, utilizando una metodología activa y participativa, que potencie la aplicación y desarrollo de determinadas destrezas intelectuales, tales como observar, describir, comparar, clasificar, aplicar conocimientos, relacionar, elaborar hipótesis, comprobar, buscar y seleccionar información, sacar conclusiones y, en definitiva, interpretar los objetos relacionándolos con el conocimiento teórico disciplinar que ya tienen.

La educación formal se da cuando las visitas son programadas por los profesores o por la institución educativa que decide el contenido de la visita que se va a realizar de acuerdo con la oferta del museo y los contenidos educativos que desean desarrollar. En este caso, las visitas deben ser preparadas por el profesor y por el museo. El museo debe ser una institución puertas afuera, considerando que debe realizar acciones para promocionarse a las instituciones educativas para hacerles recordar de su existencia, ofrecer sus servicios. Para ello deben de preparar diversos recursos didácticos (escrito, audiovisual, entre otros, a través de guías o manuales) para los profesores y para los estudiantes.
Para desarrollar programas educativos dentro de la educación formal se tiene que considerar el público destinatario, el lugar donde se realizan, los objetivos, las estrategias educativas que permitan generar una estrecha relación entre el museo y la institución educativa, teniendo en cuenta que este llegue a ser un apoyo para el profesor en la tarea educativa. Los programas deben ser dirigidos y estructurados en concordancia con los diseños curriculares de las instituciones educativas, de modo que facilite el aprendizaje formal y la exposición sea el canal conductor para reforzar o apoyar los conocimientos adquiridos en clase.

Fernández y Rubio (2013, p. 8) consideran que, para implementar programas educativos en el ámbito de la educación formal en los museos, es necesario tener en cuenta lo siguiente:

- Conocimientos previos de los estudiantes a nivel curricular.

- Capacidades y habilidades procedimentales.

- Adaptación de los contenidos de las actividades propuestas a los contenidos curriculares de los diversos niveles educativos.

- Adaptación de las actividades al nivel del desarrollo cognitivo y a la capacidad de abstracción de los estudiantes.

Las principales actividades que se desarrollan dentro de la educación formal son las siguientes (Fernández y Rubio, 2013):

1. Recorridos didácticos: por las salas de exposición con grupos de estudiantes de instituciones educativas Se interactúa con la participación a través de preguntas y respuestas. Se puede utilizar material de apoyo como láminas de distinto tipo (mapas, dibujos, imágenes de objetos, etc.).

2. Visitas teatralizadas: este tipo de visita se realiza mediante la utilización de textos literarios o de recreación histórica, creados ex profeso, para establecer conexión entre el patrimonio material $e$ inmaterial. El objetivo principal es contextualizarlos en el tiempo y el espacio. Estas visitas cuentan con dos etapas: 
a. Monólogo teatralizado: los estudiantes son los espectadores, pero pueden ser participantes de la obra.

b. Visita autogestionada: actividad práctica en las salas de exposición, para ello los estudiantes completan unas fichas didácticas con el apoyo de mediadores.

3. Visitas - taller: consta de dos partes, la primera es la visita a las salas de exposición y la segunda es una actividad práctica y experimental en un área destinada para ello, con la finalidad de reforzar los conocimientos adquiridos.

La educación formal está orientada principalmente a los estudiantes de las instituciones educativas a nivel escolar y universitario.

\section{LA EDUCACIÓN NO FORMAL EN LOS MUSEOS}

La educación no formal es toda actividad organizada, sistemática y educativa realizada fuera del marco del sistema oficial, con el fin de facilitar determinadas clases de aprendizajes a subgrupos particulares de la población, tanto adultos como niños. Se refiere a todas aquellas instituciones, actividades, medios, ámbitos de educación que, no siendo escolares, se han creado expresamente para satisfacer determinados objetivos educativos, por ejemplo, cursos de idiomas, clases de música y diplomados, entre otras. (Reynoso, 2013).

La educación no formal en el museo se centraliza en los programas públicos, de acción cultural, en donde los visitantes participan voluntaria y libremente, de acuerdo con sus propios intereses y disponibilidad de tiempo (García 2013, p.12). Estos programas se dan debido a la necesidad de adaptar el discurso expositivo a determinados tipos de público o a ampliarlo, de acuerdo a lo que desean saber, se dirige a segmentos determinados (dependiendo de los contenidos conceptuales en razón de lo que ofrece la exposición o por la dificultad que tienen de acceder a ellos).
Cada programa cultural se inicia por alguna razón determinada y se concibe para un público concreto, cuyas necesidades, intereses, destrezas y experiencias se conocen previamente para tenerlos en cuenta a la hora de definir los objetivos, contenidos, metodología, materiales didácticos, agente educativo, tipo de actividad, lugar de realización, tiempo, duración y frecuencia.

Los programas educativos para la educación no formal contempla un público más amplio, debido a que no solo se limita a los estudiantes sino se orientan a un segmento específico de público, donde estos van a los museos por propia voluntad en su tiempo libre y/o por diversos motivos como disfrutar de un ambiente especial, entre otros.

Las actividades más habituales que se desarrollan en relación con la educación no formal son las siguientes (Fernández y Rubio, 2013):

1. Visitas guiadas: requiere la presencia de un mediador que pueda transmitir la información del material que se expone. El objetivo es atraer a nuevos visitantes y mejorar la comprensión de diversos aspectos de la exposición.

2. Visitas participativas: se emplea la interpretación basada en el conocimiento de la psicología del visitante y en la aplicación de técnicas de comunicación adecuadas que le dan sentido a las piezas, revelando la esencia de su significado, a través de "pistas" o "claves" que brinde el mediador para que se produzca una revelación.

3. Visitas singulares: actividad que consiste en una disertación o breve conferencia a "pie de vitrina" sobre una pieza en especial.

4. Visitas autogestionadas: se realiza un recorrido autónomo por las salas de exposición para conocer un conjunto determinado de objetos preseleccionados en relación a un tema o período cultural, en base a un guión 
didáctico preestablecido, que permite realizar la visita de manera libre $e$ independiente.

5. Visitas teatralizadas: conexión a través de las artes escénicas, entre los relatos y el patrimonio cultural que el museo custodia. El objetivo de las teatralizaciones es permitir contextualizar los objetos en el tiempo y en el espacio partiendo del relato. Permiten despertar el interés y la curiosidad por los objetos relacionados con el relato y animan a disfrutar de su contemplación y a profundizar sobre su significado.

6. Visitas - taller: comprende la visita a las salas de exposición y una actividad práctica. Según (Fernández y Rubio 2013, p. 29), los objetivos primordiales son:

- Que los participantes comprendan, a través de la observación de los objetos expuestos, para qué sirvieron, cuáles fueron sus usos y su historia y la importancia que tuvieron y tienen hoy en día, no solo como elemento de expresión artística, sino también como documentos que nos acercan a la comprensión de la vida cotidiana de los hombres y mujeres que nos han precedido en la historia.

- Que lleguen a conocer la técnica de elaboración de los objetos seleccionados a través del conocimiento teórico y práctico del proceso.

Otro objetivo es facilitar la familiarización con los materiales naturales, materia prima con la que se creaban objetos de gran belleza, y con las herramientas profesionales, siempre que se pueda.

El aprendizaje no formal y no tradicional en los museos representa una oportunidad especialmente adecuada a los adultos, a través de una forma activa, con propuestas diferentes, capaces de tratar problemas de los adultos en diversos ámbitos. Un aspecto de gran importancia para los adultos es que puede reportar beneficios socioculturales como: combatir la exclusión social, promover una ciudadanía activa, apoyar el desarrollo personal, promover la innovación, ofrecer oportunidades de formación a todos los individuos, entre otras.

La educación no formal en los museos se orienta a los adultos, familias, adolescentes o niños y niñas en su tiempo libre en el que se les facilite a los participantes el conocimiento teórico y práctico (manual) en la realización de una actividad.

\section{LA EDUCACIÓN INFORMAL EN LOS MUSEOS}

La educación informal es un proceso que dura toda la vida, en el que las personas adquieren y acumulan conocimientos, habilidades, actitudes y modos de discernimiento mediante las experiencias diarias y su relación con el medio ambiente. (Reynoso, 2013).

En el museo, la educación informal se puede apreciar en el interés y la atención que puedan tener los visitantes, generándoles diversos tipos de satisfacciones de manera emocional y cognitiva para su entendimiento y comprensión, con un lenguaje claro y fácil de decodificar, así como un adecuado recorrido. Es por ello que el museo debe ser una fuente incesante de comunicación, información y motivación para aprender.

Dierking (citado por García, 2013, p. 6) alude que existe un amplio debate $y$ confusión respecto a la utilización del término aprendizaje en el museo y entiende, por su parte, que aprender en el museo no es adquirir nuevas ideas, sino más bien consolidar $y$ hacer evolucionar progresivamente las ideas preexistentes.

Para Screven (citado por García, 2013) el aprendizaje informal que se realiza en la exposición se caracteriza porque no sigue rígidamente una línea o estructura, sino que es voluntario, exploratorio y adaptado al interés propio de cada persona. El público en una exposición puede hacer un recorrido 
improvisado y decidido por ellos mismos, puede estar en ella el tiempo que quiera y mientras quiera, puede pararse a leer o ver aquello que le atrae. Y todo ello estará influenciado en gran medida por sus expectativas, motivaciones, compañía con la que haga la visita, hábitos culturales, etc. Es también un acto espontáneo, realizado de manera relajada, sin presiones, sin miedos o amenazada. Es por ello que los responsables de las exposiciones están obligados a plantearse estrategias y recursos positivos que garanticen la atracción, atención y recepción del mensaje por parte del visitante.

Es preciso plantearse si se puede esperar que el museo enseñe (García, 2013), que la exposición consiga algún tipo de influencia sobre el visitante y que se produzca la deseable transmisión de conocimientos y valores acerca de las colecciones que expone. Existe cierto acuerdo en que las exposiciones que reúnen determinadas características favorecen los procesos de aprendizaje, que son los siguientes:

- El tema de la exposición responde a las preocupaciones e intereses de los visitantes, porque ello supone que tienen ciertos conocimientos $y$ actitudes positivas respecto al mismo.

- Laexposición atraey retienela atención de los visitantes interpelándolos, seduciéndolos, asombrándolos, provocándolos, entre otros, de modo que los implique emocional y cognitivamente, condición para que se pongan en marcha procedimientos de entendimiento y comprensión.

- Los contenidos de la exposición estén bien estructurados y son inteligibles $y$ comprensibles, sin que ello requiera mucho esfuerzo por parte del visitante, que desea aprender sin mucho esfuerzo.

- El recorrido propuesto sea identificable, aunque no se obligue al visitante a recorrerlo para que tenga la libertad de reconstruir su propia exposición a partir de la propuesta. (García, 2013, pp. 7-8)
Para Rieu (citado por García 2013) el museo es más que enseñar como la escuela, debe proponerse comunicar, informar y motivar a aprender. La exposición puede transmitir el saber poniendo en escena los conocimientos $y$ utilizando los diversos medios de comunicación que se integran en ella de modo que respondan a las condiciones reales de receptividad de los distintos grupos sociales, para que cada cual pueda informarse según su ritmo, necesidades, tiempo disponible y gustos. Asimismo, puede lograr que los visitantes pasen de un estado de ignorancia sobre un tema determinado a tener algún conocimiento relevante sobre él y que, además, obtengan la motivación suficiente para profundizar en ello por su propia cuenta, siempre y cuando la exposición haya conseguido conectar con sus intereses previos de descubrir, explorar, pasarlo bien, ver cosas nuevas, entre otras.

Es necesario conocer a los visitantes para poder atenderles y responder a sus necesidades. Motivar, atraer, retener, interesar, informar y procurar una experiencia gratificante al visitante va a ser, en síntesis, las actuaciones que requiere la nueva conceptualización del aprendizaje informal en el museo.

Para la educación informal, la exposición es uno de los pilares más importantes, ya que esta atrae permanentemente la atención del visitante y logra que este pase de un previo conocimiento a un deseo de saber y conocer más, además, si existiera una información errada como conocimiento previo, esta pueda ser reestructurada a partir del planteamiento general de la exposición. La exposición es en síntesis el resultado de una interacción personal entre el visitante y la propia exposición.

\section{LA LABOR DEL EDUCADOR DE MUSEOS}

El museo es una institución cuya actividad es crucial para el desarrollo cultural e intelectual de la población debido a que contribuye a desarrollar las habilidades intelectuales de las personas, al crecimiento de su autonomía y al aumento de su autoestima, a su desarrollo personal y social, a la interpretación del 
mundo, favorecer su integración a la sociedad, entre otras.

El educador de museos tiene como función principal orientar adecuadamente el tipo de aprendizaje que debe instituirse en la institución museística, considerando siempre el tipo de público y la actividad a desarrollar, para ello se cuenta con el aprendizaje por descubrimiento, aprendizaje significativo $y$ aprendizaje constructivo. Asimismo han influido notablemente en mejorar la calidad comunicativa en la institución museística.

El aprendizaje por descubrimiento se basa en el método de investigación que permite interpretar los objetos históricos. Es útil para obtener objetivos cognitivos, conceptuales y procedimentales, que van a permitir, a través de las piezas, construir conceptos para organizar, realizar y llegar a dominar las operaciones intelectuales (elaborar hipótesis, predecir, observar, identificar, describir, comparar, clasificar, documentarse, imaginar, comprobar, reflexionar, argumentar, etc.).

Según García (2013), el método de aprendizaje por descubrimiento consiste en un conjunto de actividades realizadas secuencialmente con el fin de lograr los conocimientos procedimentales necesarios para elaborar determinados conceptos a partir del patrimonio cultural, a los que se conceptualiza como documentos. Se valida a partir de enseñar a aprender con los objetos mediante la aplicación de determinadas destrezas intelectuales sobre la adquisición de conceptos acerca de ellos.

Toda esta metodología por descubrimiento es aplicable a contextos educativos formales y no formales, lo que conduce a aprender automáticamente en el museo, conociendo el lenguaje propio de los objetos y descifrando adecuadamente su significado. Cabe precisar que no es requisito que se cumpla todo el proceso, cada fase puede aprenderse independientemente, de acuerdo al nivel intelectual de cada estudiante. Este método es idóneo para ser utilizado en entornos no formales a través de visitas-taller, visitas para familias, entre otras.
Para que se produzca aprendizaje significativo en el museo, según García (2013), es necesario que las piezas expuestas sean significativas para los visitantes, de manera que, apelando a sus conocimientos o experiencia vital puedan reconocer algo en ellas y puedan percibir las peculiaridades que los diferencian. Es precisamente este juego entre lo semejante y lo diferente, lo conocido y lo desconocido, lo sabido y lo nuevo lo que despierta la curiosidad y permite iniciar la indagación basándose en los conocimientos previos, por un lado, y por otro, en el deseo de hallar respuestas a los interrogantes. Los objetos son un gran estímulo para el conocimiento porque despiertan el deseo de saber algo más sobre ellos.

La teoría del aprendizaje significativo parte de la premisa que el sujeto pueda relacionar los nuevos conocimientos, a partir de los objetos que se encuentran en el museo con los conocimientos que ya cuenta a partir de sus conocimientos teóricos, su bagaje cultural o su experiencia de vida, de modo tal que adquieran un significado en relación a ellos.

El proceso de investigación necesario a implementar en las salas de exposición requiere de ciertas actividades que permitan brindar soluciones a los visitantes y puedan conseguir un adecuado aprendizaje significativo. Para ello se mencionan las siguientes actividades inherentes:

1. La observación, descripción e identificación.

2. El registro.

3. La comparación y clasificación de los objetos.

4. La interpretación.

5. La contrastación.

Para poder plantear adecuadamente un aprendizaje experimental en el museo se debe de considerar las diferentes edades de los destinatarios a fin de que el aprendizaje sea pertinente. Para ello, se ha clasificado de la siguiente manera de acuerdo a lo planteado por Zubiaur (2004):

1. Para el grupo de educación infantil (5 6 años), la base del programa educativo 
será el juego, que puede ser exploratorio, dramático, simbólico, constructivo o físico, debido a que es el modo de aprender que tiene el niño en esta fase de su vida. El aprendizaje se basará en la observación y exploración del patrimonio cultural y espacios mediante los sentidos, para ello los niños podrán tocar, oler, escuchar, es decir, sentir los objetos y materiales del museo (réplicas). Los niños deberán experimentar libremente con materiales muy diversos y adecuados, para que el niño pueda ver, tocar, participar, actuar y aprender por sí mismo sin miedo.

2. Para el grupo de educación primaria (7 - 12 años) se les debe enseñar "como mirar", sacándolos de su pasividad y aburrimiento y brindándoles la oportunidad de tener una experiencia tangible y física. A partir de una exploración física se les ayudará a reconstruir el pasado facilitándoles el contexto mediante materiales didácticos (escritos, audiovisuales o informáticos).

3. Para el grupo de enseñanza secundaria (13 - 16 años) se le debe hacer partícipe de la planificación de las actividades dirigidas a ellos para favorecer su implicación personal y hacerles sentirse "dueños" de su propia formación, aprovechar las temáticas o exposiciones que han suscitado su interés para profundizar en ellos; así como consolidar grupos de trabajo eficaces $y$ estables.

4. La oferta educativa para adultos comprende los siguientes segmentos de población:

- $\quad$ El grupo de edad de 25 a 40 años.

- Adultos mayores.

- Las familias acompañados de sus hijos.

- Grupos específicos o "nuevos públicos", tales como profesionales, miembros de asociaciones diversas, amas de casa, grupos juveniles, militares, grupos marginales, entre otros.

El adulto suele ser un "aprendiz no guiado", disfruta de su autonomía. El aprendizaje del visitante adulto es no lineal; voluntario; con ritmo propio en función de su interés, el tiempo disponible de visita, el nivel formativo, entre otros. Es de carácter exploratorio y tiene una orientación predominantemente visual.

Laatención dela diversidad desde laperspectiva inclusiva, a través del enfoque educativo, brinda una respuesta a la interculturalidad, permite la inclusión efectiva de los estudiantes con dificultades de aprendizaje y/o procedencias sociales o culturas distintas en el flujo común y general de la escuela. Lo cual solo será posible si se produce un cambio en la mentalidad de los profesores, administración y padres como en las prácticas de enseñanza - aprendizaje desarrolladas en las aulas.

Todos los programas educativos que se generen en los museos dentro de la educación formal y no formal deben de atender a la diversidad de visitantes, teniendo en cuenta la inmigración, los diferentes tipos de familias, la mujer trabajadora, grupos desventajados, el derecho de todas las niñas y niños a recibir una educación, minorías étnicas, poblaciones afectadas por conflictos, los portadores de sida, las personas con problemas de salud, las personas con necesidades educativas especiales de aprendizaje, entre otros.

Cada grupo de edad tiene características definidas, las cuales deben de considerarse para que las actividades a desarrollarse en los museos sean eficientes y permitan que la educación formal, no formal e informal sea parte de un esfuerzo entre las instituciones educativas, museos, profesores y estudiantes, capaces de lograr los objetivos para el desarrollo personal, social y cultural de cada uno de los ciudadanos.

Considerando la diversidad de público que llega a los museos, es primordial que no existan barreras para que la institución museística permita la integración con toda la comunidad en general, es así como debe permitir adecuadas condiciones de accesibilidad física y de comunicación. Para ello existen aspectos de carácterarquitectónico, señalización interiorcon simbología estandarizada internacionalmente, 
leguaje de signos, servicios y tecnologías para favorecer la accesibilidad sensorial, que deben ser acondicionados en los museos para que los visitantes puedan desplazarse de manera autónoma, como la facilidad de acceso a la información, la facilidad para recibir información y comprenderla durante el desplazamiento, facilidad para acceder a los sistemas y servicios de uso público.

Los recursos más accesibles para los museos son los siguientes: personal especialista en lenguaje de signos, idiomas, educación, etc.; auto descripciones; documentos sonoros; audio guías, documentos en Braille; perros guía; video guías interactivas; guías para Smartphone y Iphone con pantalla táctil; signo guía; bucles de inducción magnéticos; íconos de estándar internacional; subtitulado; lectura fácil; lenguaje inclusivo, no sexista y no discriminatorio; web accesible; visita virtual; programaciones didácticas elaboradas en función del público destinatario.

\section{LOS VISITANTES DE MUSEOS}

El museo tiene como función principal atender respetuosa y responsablemente a los visitantes que llegan a sus instalaciones y además tiene la misión fundamental de conectarse con los visitantes, permitiendo que reaccionen a las percepciones, deseos y necesidades de todos aquellos que lleguen a la institución museística.

La obligación principal del museo es acercar $y$ difundir el arte, en cualquiera de sus expresiones a los visitantes, de manera amena y dinámica, como vehículo de transmisión entre dos mundos.

Inicialmente lo que se debe tener en cuenta es conocer los puntos fuertes y débiles del museo, para que se pueda realizar una adecuada planificación estratégica para mantener sus fortalezas y corregir las debilidades.

Es preciso, para todo museo, determinar los tipos de públicos que llegan a sus instalaciones, debido a que no existe un solo tipo de público y a partir de conocerlos, se puede segmentar en grupos de personas con similares deseos y necesidades para que, de esta manera, puedan reaccionar a los estímulos del museo.

Los criterios de segmentación en un museo más comunes son (Peña, 2013, p. 11):

1. Segmentación geográfica: segmentos por procedencia de público

2. Segmentación demográfica: segmentos agrupados por edad, sexo o nivel educativo.

3. Segmentación psicosocial: formada por estilos de vida o clases sociales.

4. Segmentación por comportamientos con el museo: reunidos por su grado de fidelidad (repetición visita), aportaciones, etc.

5. Segmentación geodemográfica: agrupación por perfiles (cluster).

6. Segmentación organizativa: diferenciados por el tipo de organización o función a la que pertenecen, tales como colegios, asociaciones de vecinos, periodistas, amigos del museo, entre otros.

Segmentar es muy útil, ya que a partir de ello se pueden hacer diversos estudios de público o de visitantes y así, se puede analizar mejor los comportamientos y necesidades, y prever reacciones a acciones propuestas.

Para que las exposiciones en los museos sean exitosas, las exigencias propias de estas van a traer consigo contar con un amplio equipo de especialistas tales como los científicos (historiadores, antropólogos, arqueólogos, paleontólogos, biólogos, botánicos, entre otros) conocedores del tema, educadores comunicadores, arquitectos, museólogos, museógrafos, diseñadores, evaluadores y los especialistas en marketing $y$, finalmente programar y proyectar la exposición con riguroso método a través de un equipo transdisciplinario.

Para Pérez (2013, p. 3), las características generales de los visitantes a los museos está determinada por:

1. Variables sociodemográficas: edad, género, nivel socioeconómico, nivel de instrucción educativa, etc. 
2. Hábitos de visita: visitas previas, número de visitas en el último año, visitas a otros museos, etc.

3. Aspectos relacionados con la visita: compañía durante la visita, planificación de la visita, razones de la visita, tiempo dedicado, etc.

4. Opiniones sobre el museo y la visita: preferencias, nivel de satisfacción con la visita, etc.

Los visitantes a los museos se caracterizan por su nivel de estudios y a su vez su estatus social, cultural y económico medio - alto, lo que origina situaciones discriminadoras que necesariamente requieren ser corregidas para facilitar el acceso de todos los ciudadanos. De ese modo, se favorece la inclusión social a través de políticas dirigidas a potenciar el número de público visitante y generar el impulso de participación ciudadana con una nueva definición del papel de los museos en la sociedad. Los museos deben ser considerados agentes de cohesión e integración social, ya que posibilitan el conocimiento de la identidad cultural, al mismo tiempo que fomentan la reflexión sobre lo compartido y el respeto por la diversidad. (Hooper-Greenhill, Sandell, Moussouri y O'Riain, 2010).

Entre los grupos de visitantes a los museos de mayor importancia están aquellos que fluctúan entre los 25 y 45 años de edad y los niños (podrían catalogarse como visitas de familias). La mayoría de personas van a los museos acompañadas de familiares y amigos principalmente, cuentan con alto nivel de instrucción y tienen una edad media en torno a los 30 años.

A lo largo de los años se ha generado la creencia de que en los museos de arte cuentan con un público más instruido y exclusivo, mientras que los museos de ciencias o los centros de interpretación ambiental y científica posee un público más semejante a la población general. Consecuentemente, los públicos de los museos, sea cual sea su temática, tienden a pertenecer, en mayor o menor medida, a grupos de élite social, económica y cultural.
Las características psicológicas, según Hood, son más relevantes que las sociodemográficas para explicar las diferencias entre visitantes y no visitantes. Los visitantes asiduos, los ocasionales y los no visitantes difieren en sus estilos de ocio y en la orientación que imprimen a sus visitas al museo (Pérez, 2013, p. 6):

1. Los visitantes asiduos de museos relacionan el ocio con la oportunidad de aprender, cambiar o tener nuevas experiencias.

2. Los visitantes ocasionales y no visitantes lo hacen con sentimientos de confort, "estar a gusto" con su alrededor, participar activamente en algo y compartir experiencias con otras personas.

Según Hood (citado por Pérez, 2013, p. 6) existen seis aspectos importantes que los adultos toman en cuenta para participar o no en actividades de ocio:

1. Estar con gente.

2. Hacer algo que merezca la pena para uno mismo o para otros.

3. Sentirse confortable y a gusto con lo que lo rodea.

4. Experimentar el reto de nuevas experiencias.

5. Tener una oportunidad para aprender.

6. Participar activamente.

Generalmente las personas que van a los museos cuentan con una percepción previa que son el resultado de su propia experiencia, de lo que oyen sobre ellos, de lo que conocen de su accesibilidad, de lo que les ofrecen, de la impresión que les haya quedado de visitas anteriores. Otro de los factores que permite que las personas vayan al museo son las recomendaciones personales.

Los casos en los cuales las experiencias son negativas, se deben a que las personas no conocen ciertos "códigos museísticos" de los objetos, el lenguaje y símbolos. Por lo cual se convierte en algo intimidatorio, remoto y difícil de descifrar.

Los visitantes, generalmente no invierten más de dos horas en un museo, de los cuales cerca 
de cuarenta y cinco minutos los dedican para ir a los servicios higiénicos, tienda o cafetería. Los visitantes de una exposición, dejan zonas enteras sin visitar, principalmente por la inexistencia de un recorrido claro. Los visitantes se sienten más atraídos por recorridos donde se hallen objetos conocidos o importantes, objetos móviles o animales, sonidos y objetos de gran tamaño.

De acuerdo a los estudios de públicos, se puede concluir que los grupos que se excluyen de visitar los museos son los siguientes (Pérez, 2013, p.13):

a. Jóvenes: descenso demográfico que permite demostrar la baja en la visita a los museos.

b. Mayores de 65 años y jubilados: disponen de la mayor cantidad de tiempo y cuya ausencia en los museos puede relacionarse a las carencias educativas de generaciones anteriores, así como el cansancio y las dificultades de desplazamiento derivadas de su edad.

c. Desempleados.

d. Extranjeros residentes en el país que procedan de países de emigración socio-económica y los ciudadanos de bajo nivel de estudios.

e. Turistas extranjeros con dificultades lingüísticas.

f. Personas con discapacidades y necesidades específicas de integración social.

g. Niños menores de 12 años.

McManus (citado por Pérez, 2013, p. 19) halló que los visitantes, durante su recorrido en un museo, se comportan de manera distinta según el grupo que componen:

- Grupos con niños: hablan bastante tiempo de las cosas que ven y hacen, pero prestan poca atención a los textos.

- Solitarios: dedica más tiempo a la exposición que ningún otro tipo, lee los textos, pero utiliza poco los elementos interactivos.

- Parejas de adultos: dedican gran cantidad de tiempo a la exposición, leen con atención los textos, pero no suelen hablar entre ellos sobre la exposición.

- Grupos de adultos: prestan una menor atención a la exposición que los demás grupos y tienden a no leer los textos.

\section{DIDÁCTICA EN EL MUSEO}

La didáctica se encuentra íntimamente relacionado con los términos enseñar, instruir, exponer con claridad (Santacana y Serrat, 2007), asimismo Comenio (1986, p. 163) considera enseñar como el "artificio universal para enseñar todas las cosas a todos con rapidez, alegría y eficacia". A través de esta definición se quiere dar a conocer qué debe ser enseñado por el docente y mediante qué medios.

De acuerdo a lo expresado por Comenio, al decir 'rápida' se remite a la necesidad de transmitir y mostrar una idea evitando el camino más largo, intuyendo en primera instancia aquellas vías de fácil comprensión para los ciudadanos a quienes nos dirigimos. El término 'alegría' nos remite a la necesidad de incorporar aquellos recursos que eviten el tedio y el aburrimiento, de manera que los visitantes no sufran en el momento de percibir aquello que se le muestra. El concepto 'eficaz' se refiere al hecho de que se necesita que la acción de mostrar las cosas a todos logre los resultados más favorables. (Santacana y Serrat, 2007).

Santacana y Serrat consideran que, para que exista una adecuada acción didáctica en la institución museística, debe centrarse en la presentación $y$ en el tratamiento didáctico del material cultural que se expone y contextualizarlo dentro de los aspectos sociales, culturales, históricos e ideológicos. Asimismo, debe existir una motivación inicial de los alumnos para el proceso de aprendizaje. Igualmente, los principios didácticos tienen que ser relativos al maestro, al alumno o visitante, a las materias de enseñanza y al entorno.

Una acción didáctica concreta de un programa educativo, independientemente del tipo de público al que se dirija, debe de centrarse en lo siguiente (Santacana y Serrat, 2007, p. 116): 
- Los contenidos deben ser asequibles al nivel al que van dirigidos, además, adaptarse a los intereses y naturaleza del grupo.

- Se debe favorecer en lo posible el contacto con el patrimonio cultural, potenciando el diálogo entre los visitantes y las colecciones de manera que sean ellos los artífices de su propio aprendizaje y que la función del monitor/profesor se limite a animar la visita.

- Las actividades educativas no deben dirigirse solamente hacia la información; también deben estimular la curiosidad.

- La estructuración de las actividades debe ser flexible, de tal forma que el interés no decaiga y se mantenga un ambiente distendido a lo largo de toda la actividad.

- No se deben olvidar otros valores, como el trabajo en grupo o el respeto hacia otras opiniones, culturas y hacia el patrimonio histórico - artístico.

La actividad didáctica relativa al contexto expositivo y a la presentación de los temas que expone un museo debe ser reconocible por los visitantes para que este tenga un sentido. Debe ser atractivo y debe presentar actitudes positivas con una historia bien contada, con un desarrollo de temas y subtemas, con ideas y conceptos claros y precisos. La estructura del discurso debe dotarlo de continuidad, sin que este contenga elementos que sobren o espacios vacíos.

El patrimonio cultural que se presenta dentro del discurso museográfico debe tener coherencia entre ideas y conceptos, lo que va a dar el significado a la exposición. Para ello, todo lo que se muestra en una exposición debe presentarse en su contexto original, porque se muestra su función tal como se utilizó.

Es necesario contar con la información necesaria dentro de la exposición y que esté en los textos, imágenes, infografías, elementos escenográficos, entre otros, integrándose entre sí y yendo de la mano para que se entiendan y comprendan los significados y valores que la exposición desea transmitir.
Los textos son una parte esencial de la exposición porque ofrecen información a los visitantes. Son un recurso eficaz para el aprendizaje, asimismo, brindan condiciones de entrada, son instructivos, indican circulación, orientación, están presentes en los paneles informativos y explicativos, en las cartelas, entre otros.

Existen factores que favorecen la lectura y estos deben estar presentes en la exposición (García, 2013):

1. Confort visual:

- Debe existir contraste entre el color de fondo y el texto.

- Tamaño de los caracteres adecuados, no debe ser nunca inferior a 18 .

- Longitud de línea de máximo diez a doce palabras.

- Espaciado de líneas armonioso.

- Párrafos de cuatro a cinco líneas.

- Frases cortas y simples.

2. Concisión y claridad:

- Los textos deben desarrollar estrictamente el tema.

- Permitir una lectura rápida y compartida.

3. Precisión:

- Que las palabras nuevas queden definidas, se visualicen y se repitan, que en ningún caso se abuse de palabras científicas, debido a que el texto se torna incomprensible.

4. Extensión:

- Brevedad en el texto.

- Utilización de 75 palabras por texto.

- Títulos y subtítulos con 10 palabras como máximo.

- Textos introductorios y explicativos que no sobrepasen las 100 palabras.

- Longitud máxima por línea de 65 caracteres o de 8 a 15 palabras por línea.

5. Señalización:

- Utilización de frases temáticas al inicio del párrafo.

- Colocar palabras esenciales al inicio de la frase. 
Los medios gráficos son otros de los elementos necesarios para las exposiciones que están constituidas principalmente por dibujos, infografías, fotografías, mapas, esquemas, diagramas, entre otros. Todos estos elementos para que sean realmente de utilidad es necesario que no presenten detalles inútiles, su interpretación sea directa y fácilmente reconocida, familiar y atractiva a todo tipo de público. Igualmente, los audiovisuales son dispositivos que integran la exposición, deben ser legibles y atractivos, mediante imágenes reconocibles por sí mismas y el mensaje oral $y$ visual sea totalmente comprensible por los visitantes.

El ámbito escenográfico permite brindar presentación tridimensional de aspectos relacionados con la exposición mediante modelos, maquetas, dioramas, ambientes, reproducciones, paisajes urbanos, entre otros, que facilitan la comprensión del planteamiento de investigación realizado.

\section{LOS MUSEOS PERUANOS: UNA TAREA PENDIENTE}

En general, los museos en el Perú cuentan con un número reducido de profesionales y técnicos para cumplir sus funciones, por lo cual, la multifunción una práctica frecuente. Por ello, la mayoría de instituciones museísticas carecen de personal capacitado en la función educativa. En el Perú no se cuenta con una formación académica en educación en museos o pedagogía museística.

Uno de los grandes inconvenientes que afrontan los museos en la actualidad es la falta de recursos económicos. En los museos de administración estatal, la escasez de recursos implica el poco fortalecimiento de la institución museística con la comunidad, donde uno de los aspectos principales es la apropiación cultural y social. En el caso de los museos privados, los recursos limitados se deben, principalmente, a que son iniciativas de coleccionistas o asociaciones civiles que cuentan con inversionistas o amigos de los museos que los apoyan.

Las instituciones museísticas coinciden en que la función educativa es de gran relevancia social y cultural para sus fines, pero, lamentablemente las autoridades, en el caso estatal, no tienen la conciencia clara sobre la importancia de contar con un departamento o una jefatura de educación y acción cultural que tenga como finalidad esencial la tarea educativa, cultural y social.

Un departamento educativo bien estructurado deben contar con un equipo transdisciplinario para planificar, investigar, diseñar y ejecutar los programas educativos para todo tipo de visitante que llegue al museo. A su vez, deben ocupar un sitial preponderante dentro de la institución museística creando exposiciones y programas que fomenten una mirada crítica en los ciudadanos.

Es necesario reconocer que se cuentan con museos que realizan actividades educativas con los visitantes. Es el caso del Museo de Arte de Lima, Museo Nacional de la Cultura Peruana, Museo Pedro de Osma, Museo de Arte Contemporáneo, entre otros. Esas actividades les permiten brindar herramientas $y$ recursos de aprendizaje en contacto directo con el patrimonio cultural.

Finalmente, es necesario crear conciencia hacia las instituciones que administran los museos en el Perú para que logren, de manera eficaz, la inclusión del agente educativo en los museos. Asimismo, preparar adecuadamente a los docentes de las escuelas primarias, secundarias y universitarias para que conozcan y generen un fortalecimiento eficiente para generar programas educativos en los museos. Esto significa contar con ellos para esa ardua tarea, teniendo en cuenta que en el Perú son extremadamente escasos los profesionales que cuentan con estudios especializados en educación o pedagogía en museos. 


\section{REFERENCIAS}

Comenio, J. (1986) Didáctica magna. Madrid, España: Akal.

Fernández, D. y Rubio, M. (2013) El museo, instrumento educativo formal y no formal. Recursos educativos del museo. Planificación y desarrollo de los programas educativos en los museos. Museología didáctica: la labor práctica de un educador en museos. Expertos en educador en museos, departamento de didáctica, Universidad de Alcalá, España.

García Blanco, A. (1988) Didáctica del Museo. El descubrimiento de los objetos. Madrid, España: Ediciones de la Torre.

García Blanco, A. (1997) Aprender con los objetos. Guía didáctica del M.A.N.

García Blanco, A. (2013) Los departamentos de educación y acción cultural. Introducción a la didáctica en el museo. Expertos en educador en museos, departamento de didáctica, Universidad de Alcalá, España.

García Blanco, A. (2013) Museos y educación: evolución de la misión educativa de los museos. La educación formal, informal y no formal en el museo. Introducción a la didáctica en el museo. Expertos en educador en museos, departamento de didáctica, Universidad de Alcalá, España.

García Blanco, A. (2013) El aprendizaje informal en la exposición. Estrategias comunicativas $y$ didácticas. Pedagogía museológica: la formación de un educador de museos. Expertos en educador en museos, departamento de didáctica, Universidad de Alcalá, España.

Hooper-Greenhill, E., Sandell, R., Moussouri, T. y O'Riain, H. (2000) Museums and Social Inclusion. The GLLAM Report. Research Centre for Museums and Galleries (RCMG), Department of Museum Studies, University of Leicester.

Lord, B. y Lord G. (2005) Manual de gestión de museos. Barcelona, España: Ariel, S.A.

Peña, V. (2013) La gestión del museo orientada a los usuarios: el museo agente cultural y transmisor de cultura. Introducción a la didáctica en el museo. Expertos en educador en museos, departamento de didáctica, Universidad de Alcalá, España.

Pérez, E. (2013) Las características de los visitantes de museos: aspectos sociodemográficos, motivacionales y psicológico. Perfiles de públicos. Comportamiento del público en los museos. Introducción a la didáctica en el museo. Expertos en educador en museos, departamento de didáctica, Universidad de Alcalá, España.

Reynoso, E. (2013) Los museos de ciencia en la sociedad de la información y el conocimiento. La educación en el museo, objeto de investigación. El museo y la escuela conversaciones de complemento. Medellín, Colombia: Claudia Aguirre - Parque Explora.

Santacana, J. y Serrat, N. (2007) Museografía didáctica. Barcelona, España: Ariel, S.A.

Screven, C. (1988) Exposiciones educativas para visitantes no guiados, la investigación del educador de museos, Conferencia ICOM/CECA`85, Barcelona, Ayuntamiento de Barcelona, $95-115$. 
Touriñan, J. (2000) Análisis teórico del carácter "forma", "no formal" e "informal" de la educación, Papers d'Educació, $n^{\circ} 1$ (1983), citado en La difusión cultural en el museo: servicios destinados al gran público. Gijón, Asturias, España: TREA, S.L.

Valdés, M. (1999) La difusión cultural en el museo: servicios destinados al gran público. Gijón, España: TREA, S.L.

Zubiaur, F. (2004) Curso de Museología. Gijón, España: TREA, S.L.

Fecha de recepción: 03 de agosto 2015

Fecha de aceptación: 26 de agosto 2015 